\title{
Factors Associated with Changes in Bone-Mass Density in Female Patients with Osteopenia Post Menopause
}

\author{
Bagus Putu Putra Suryana ${ }^{1}$, Muhammad Reza Febriliant ${ }^{2}$, Rulli Rosandi ${ }^{3}$, Sukarlin $^{4}$, Wiji Lestari ${ }^{4}$ \\ ${ }^{1}$ Division of Rheumatology Internal Medicine Departement, Faculty of Medicine, Universitas Brawijaya - RSUD Dr. Saiful Anwar Malang, Malang, Indonesia \\ ${ }^{2}$ Resident of Internal Medicine Departement, Faculty of Medicine, Universitas Brawijaya - RSUD Dr. Saiful Anwar Malang, Indonesia \\ ${ }^{3}$ Division of Endocrinology Internal Medicine Departement, Faculty of Medicine, Universitas Brawijaya - RSUD Dr. Saiful Anwar Malang, Indonesia \\ ${ }^{4}$ Nutritionist of Nutrition Installation of RSUD Dr. Saiful Anwar Malang, Malang, Indonesia
}

ARTICLE INFO

Corresponding Author:

Muhammad Reza Febriliant

Departemen of Internal Medicine,

Faculty of Medicine, Universitas

Brawijaya, Jln Jaksa Agung Suprapto.

No. 2, Malang, 65111, Indonesia

Email:

febrilianreza@gmail.com

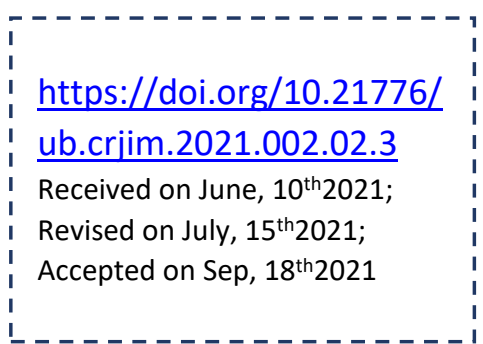

\section{A B STRACT}

Background: Many factors can cause bone mass density (BMD) changes in women with postmenopausal osteopenia.

Aim: to determine factors associated with BMD changes in osteopenia postmenopausal women determined by severe factors within 1 year.

Methods: The study was conducted on 38 patients who met the inclusion criteria and had BMD data for the last 2 years and body mass index. Interviews were conducted for physical activity, age of menopause, and duration of menopause. Blood samples were also taken to check total calcium levels, vitamin D levels and estrogen levels. Finally, patients are followed for up to 1 week for daily nutrition records. The relationship between these factors and changes in BMD was analyzed using Pearson's or Spearman's test. The analysis result was considered significant if $p<0.05$.

Results: There was no significant relationship between body mass index, menopause duration, physical activity, dietary calcium, serum calcium levels and serum estradiol levels on changes in BMD with $p$ value $>0.05$. However, there was a significant relationship between menopause onset and changes in ward mass density $(r=0,321, p=0,04)$ and lumbal $1(r=$ $0,333, p=0,04)$, serum vitamin $D$ levels and changes in great trochanter mass density $(r=$ $0,336, p=0,036)$, physical activity score and changes in ward mass density $(r=-0,522, p<0,01)$. Conclusion: menopause onset, vitamin $D$ and physical activity are significantly associated with changes in BMD in female patients with postmenopausal osteopenia.

Keywords: Osteopenia, Post menopause, BMD, estradiol, vitamin D, calcium, physical activity.

\section{N T R O D U C T I O N}

Osteoporosis is still an increasing health problem in Indonesia. Osteoporosis often considered a disease of the elderly, but it turns out that this disease can occur at a young age. Currently, the total population of Indonesia reaches 237 million people and it is

Suryana BPP, Megawanto NH, Rosandi R, et al. Factors Associated with Changes in

Bone-Mass Density in Female patients with Osteopenia Post Menopause. Clinical and

Research Journal in Internal Medicine. 2021;2(2):177-186. DOI:

https://doi.org/10.21776/ub.crjim.2021.002.02.3 
estimated that 71 million people will be over 60 years old by 2050 . It is estimated that $28.7 \%$ of men and $32.3 \%$ of women have been diagnosed with osteoporosis by means of bone mineral densitometry (BMD). However, only a few of these diseases can be diagnosed because the population is scattered distribute throughout Indonesia and some of the 34 BMD machines are located in Jakarta. ${ }^{(1,2)}$

In Indonesia, the prevalence of osteoporosis in women aged $50-80$ years is $23 \%$ and aged $70-80$ years is around 53\%.The prevalence of osteoporosis in men also increases, bone mass density decreases by 10 $20 \%$ at the age of 20-39 years and ages 70-79 years decreases by about $40 \%$. However, the risk in women is still 4 times higher than that in men. ${ }^{(1)}$

Osteopenia is a condition when bone density is abnormal but is not yet considered osteoporosis. The World Health Organization (WHO) has defined osteopenia as bone mass density with a T-Score of -1 to -2 .5.Factors that cause osteopenia include deficiency of calcium and vitamin D and lack of physical activity. In addition, genetic factors also play an important role in bone mass density. Osteopenia is common in premenopausal Caucasian women with low body weight. Correcting calcium and vitamin $D$, and walking 3-5 km per week can increase bone density in the pelvis and spine. ${ }^{(3)}$

Various therapeutic modalities have been recommended for osteopenia patients. Non-pharmacological therapy recom for osteopenia, including vitamin or calcium supplements alone, have been shown to be ineffective in reducing fracture incidence or preventing osteoporosis. The combination of calcium and vitamin $D$ was only able to reduce the risk of pelvic fracture or other fractures slightly. Pharmacologic therapy to prevent fracture in osteopenia patients is still limited and most clinical trials conducted are of therapeutic design for the osteoporosis population. Pharmacological interventions for osteopenia are controversial in terms of the cost-effectiveness of therapy. ${ }^{(4)}$

Various risk factors can be found in postmenopausal female patients who have osteopenia. Therefore, we wanted to know the factors that influence the changes in bone mass density in postmenopausal women with osteopenia in Indonesia, especially in Malang. Thus, interventions can be made to prevent these risks so that in the end the osteoporosis rate can be lowered.

The purpose of this study was to determine the factors associated with changes in bone mass density in postmenopausal women with osteopenia with the most influential risk factors within 1 year.

\section{E T H O D S}

This study was conducted using crosssectional analysis on menopausal female patients who came to the Internal Medicine Department of Saiful Anwar Hospital and obtained osteopenia conditions that match the inclusion criteria based on a list of patients who had undergone an examination with bone mineral densitometry and had agreed informed consent to participate in the study. Exclusion criteria were malignancy, steroids use, and chronic inflammatory diseases such as rheumatoid arthritis, systemic lupus erythematosus, chronic obstructive pulmonary disease, nephrotic syndrome, bone infection, and thyroid dysfunction. This study has obtained ethical clearance from the Hospital Research Ethics Commission of Dr. Saiful Anwar Hospital Malang. 
Upon initial arrival at the clinic, confirmation of patient data from the existing list was carried out, interviews were conducted regarding menstrual status, current physical activity and past physical activity history, as well as measuring body weight and height which then calculated the body mass index.

Physical activity was measured using the Bone-Specific Physical Activity Questionnaire (BPAQ).In the initial part, the interview was conducted in conjunction with recording the types of physical activity and sports that were carried out regularly from a certain age to a certain age. In the second part, also recorded physical activity and sports that were carried out routinely during the last 12 months up to the number of sessions per week. The questionnaire was asked directly by the researcher on the subject. Then, the total BPAQ was calculated using the Lab VIEW program (National Instrument, Texas, USA) created by the BPAQ developer. ${ }^{(5)}$

Then, a fasting blood serum biochemical examination was performed to determine the levels of calcium, $25(\mathrm{OH})$ vitamin $\mathrm{D}$, and levels of estrogen. All samples were examined enzymatically using an autoanalyzer in the clinical pathology laboratory of Saiful Anwar Hospital Malang. Standard laboratory procedures determine the serum level of biochemical parameters. Serum calcium is considered normal $8.6-10.2 \mathrm{mg} /$ dL.The serum calcium used was not adjusted according to the findings in previous studies ${ }^{(6)}$. Vitamin D insufficiency $(25(\mathrm{OH})$ vitamin $\mathrm{D})$ when the level is $<30 \mathrm{ng} / \mathrm{L}$, deficiency if $<20 \mathrm{ng} / \mathrm{L}$ and severe deficiency if $<10 \mathrm{ng} / \mathrm{ml}$. In postmenopausal conditions, normal serum estradiol levels were $5-54.7 \mathrm{pg} / \mathrm{mL}$.
The patient then asked to record the diet for 7 consecutive days and report it to the nutritionist who has been trained to ensure that the recording is carried out correctly. Nutritional intake is processed by Nutri survey software which has been adapted so that the calcium content consumed by the patient is obtained.

Bone mass density $\left(\mathrm{g} / \mathrm{cm}^{2}\right)$ was measured by means of dual-energy X-ray absorptiometry (DXA) at lumbar 1, lumbar 2, lumbar 3, lumbar 4, lumbar 1-4, and proximal femur (femoral neck, Ward's triangle, and the femoral trochanter).Osteopenia is defined according to World Health Organization (WHO) criteria as the T-score for bone density is at -1.0

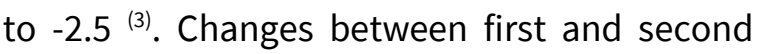
measurement were calculated.

All data are presented as means and standard deviation if the data is normally distributed or median and interquartile ranges if the data are not normally distributed. The relationship between data was tested with Pearson's or Spearman's correlation coefficient. A p-value $<0.05$ was considered statistically significant. All statistical analyzes were performed with SPSS version 26 software.

\section{RE S U L T S}

The total subjects of this study were 38 people. All subjects were over 45 years old, post menopause women, and no comorbidities that could affect the reinforcement therapy.

Based on Table 1, it is known that the mean of body mass index was $23.51 \pm 3.668$ $\mathrm{kg} / \mathrm{m}^{2}$. The mean duration of menopause was $15.74 \pm 9.607$ years. Mean serum vitamin D was $16.59 \pm 7.055 \mathrm{IU} / \mathrm{dL}$ considered as an insufficiency condition. The mean serum calcium level was $8.89 \pm 0.574 \mathrm{mg} / \mathrm{dL}$ which was classified as normal. Meanwhile, from the 
calcium diet data, the mean calcium intake was $377.88 \pm 315.495 \mathrm{mg} /$ day. This intake is still far below the reference for daily calcium intake, which is around $700-900 \mathrm{mg} /$ day. The value of physical activity score was $10.58 \pm$ 11.048. Estradiol levels with median $5.00 \mathrm{pg} / \mathrm{mL}$ with $\mathrm{g} / \mathrm{mL}$ and the highest level was $16 \mathrm{pg} / \mathrm{mL}$. This low level of estradiol is in accordance with the condition of the subject, a postmenopausal woman.

The bone mass density changes in in 1 year (2018-2019) in femur neck was $0.01 \pm 0.039$ $\mathrm{g} / \mathrm{cm}^{2}$, greatest trochanter was $0.013 \pm 0.045$ $\mathrm{g} / \mathrm{cm}^{2}$, ward was $0.044 \pm 0.095 \mathrm{~g} / \mathrm{cm}^{2}$, lumbal 1 was $0.019 \pm 0.086 \mathrm{~g} / \mathrm{cm}^{2}$, lumbal 2 was $0.004 \pm$ $0.104 \mathrm{~g} / \mathrm{cm}^{2}$, lumbal 3 was $0.001 \pm 0.091 \mathrm{~g} / \mathrm{cm}^{2}$, lumbal 4 was $0.004 \pm 0.087 \mathrm{~g} / \mathrm{cm}^{2}$, and lumbal 1 4 was $-0.001 \mathrm{~g} / \mathrm{cm}^{2}$ with the smallest change was $-0.08 \mathrm{~g} / \mathrm{cm}^{2}$ and the largest change was $0.290 \mathrm{~g} / \mathrm{cm}^{2}$. From the results of the average changes in bone mass density, positive results were obtained in all areas carried out by BMD which showed that bone mass density in 2019 increased compared to bone mass density in 2018. Changes in bone mass density can be seen in Table 2 and Table 3.
Table 1. Clinical Characteristics of Study Subject

\begin{tabular}{|c|c|}
\hline Characteristics & $\mathrm{n}=38(\%)$ or mean \pm SD \\
\hline Age & $66.5 \pm 8.60$ year \\
\hline Body Mass Indexes & $23.54 \pm 3.74 \mathrm{~kg} / \mathrm{m}^{2}$ \\
\hline Vitamin D Serum & $16.59 \pm 7.15 \mathrm{IU} / \mathrm{dL}$ \\
\hline Calcium Serum & $8.89 \pm 0.58 \mathrm{mg} / \mathrm{dL}$ \\
\hline Calcium Diet & $383.7412 \pm 317.57 \mathrm{mg} / \mathrm{day}$ \\
\hline Physical Activity Score (BPAQ) & $10.810 \pm 11.10$ \\
\hline \multicolumn{2}{|l|}{ Monthly Income (Rupiah) } \\
\hline 0 - 5 million & $24(63.2)$ \\
\hline 5 - 10 million & $10(26.3)$ \\
\hline $10-15$ million & $2(5.3)$ \\
\hline Above 15 million & $2(5.3)$ \\
\hline \multicolumn{2}{|l|}{ Menopause Status } \\
\hline Onset of Menopause & $51 \pm 3.85$ year \\
\hline Duration of Menopause & $15.50 \pm 9.613$ year \\
\hline Estradiol Serum & $5.00(5-16) \mathrm{pg} / \mathrm{mL}$ \\
\hline \multicolumn{2}{|l|}{ Employment History } \\
\hline Housewife & $15(39.5)$ \\
\hline Government officials & $15(39.5)$ \\
\hline General Employees & $5(13.1)$ \\
\hline Trading & $2(5.3)$ \\
\hline Sewing & $1(2.6)$ \\
\hline \multicolumn{2}{|l|}{ Routine Medication } \\
\hline Anti-Hypertension & $30(78.9)$ \\
\hline Calcium Supplement & $24(63.2)$ \\
\hline Bisphosphonate & $15(39.5)$ \\
\hline Anti-Diabetes & $15(39.5)$ \\
\hline Vitamin and Supplement & $8(21.1)$ \\
\hline Anti-dyslipidemia & $7(18.4)$ \\
\hline Vitamin D & $7(18.4)$ \\
\hline Pain Reliever & $7(18.4)$ \\
\hline Proton Pump Inhibitor & $4(10.4)$ \\
\hline Anti-Hyperuricemia & $3(7.9)$ \\
\hline Clopidogrel & $2(5.3)$ \\
\hline Anti-Asthma & $2(5.3)$ \\
\hline Acetylsalicylic acid & $1(2.6)$ \\
\hline Sedatives & $1(2.6)$ \\
\hline Others & $3(7.9)$ \\
\hline
\end{tabular}

BPAQ: Bone-Specific Physical Activity Questionnaire

Table 2. The Mean of Changes in Bone Mass Density

\begin{tabular}{cccc}
\hline Location & \multicolumn{2}{c}{ Bone Mineral Density $\mathbf{( g / \mathbf { c m } ^ { 2 } )}$} & Changes \\
& Year 1 (mean \pm SD) & Year 2 (mean \pm SD) & $0.013 \pm 0.045$ \\
\hline Great Trochanter & $0.555 \pm 0.074$ & $0.568 \pm 0.081$ & $0.044 \pm 0.095$ \\
Ward & $0.49 \pm 0.09$ & $0.534 \pm 0.097$ & $0.019 \pm 0.086$ \\
Lumbal 1 & $0.566 \pm 0.081$ & $0.585 \pm 0.106$ & $0.004 \pm 0.104$ \\
Lumbal 2 & $0.656 \pm 0.119$ & $0.66 \pm 0.107$ & $0.001 \pm 0.091$ \\
Lumbal 3 & $0.717 \pm 0.106$ & $0.718 \pm 0.093$ & $0.004 \pm 0.087$ \\
Lumbal 4 & $0.729 \pm 0.093$ & $0.733 \pm 0.091$ & \\
\hline
\end{tabular}


Table 3. Median Changes in Bone Mass Density

\begin{tabular}{cccc}
\hline \multirow{2}{*}{ Location } & \multicolumn{2}{c}{ Bone Mineral Density $\left(\mathbf{g} / \mathbf{c m}^{\mathbf{2}}\right)$} & Changes \\
& Year 1 (median) & Year 2 (median) & (median) \\
\hline Lumbal 1-4 & $0.665(0.54-0.92)$ & $0.665(0.55-0.89)$ & $-0.001(-0.080-0.290)$ \\
\hline
\end{tabular}

In the bone area that was examined, bone mass density was found to be statistically significant with the onset of menopause, serum vitamin $\mathrm{D}$ levels and physical activity values. There was a significant correlation with positive correlation and moderate correlation strength on menopause onset with Ward and lumbar bone mass density 1 (Figure 1 and Figure 2).There was a significant correlation with positive correlation and moderate correlation strength between serum vitamin D levels and changes in great trochanter bone mass density (Figure 3).There was also a significant relationship with negative correlation and strong correlation between the value of physical activity and changes in Ward's bone mass density (Figure 4).The relationship between changes in bone mass density and other variables is shown in Table 4.

\section{DISCUSSIONS}

In Indonesia, the results of the analysis of osteoporosis risk data in 2005 with a sample size of 65,727 people conducted by the Ministry of Health's Nutrition Research and Development Center and a nutrition company showed that the prevalence rate of osteopenia was $41.7 \%$ and the prevalence of osteoporosis was $10.3 \%$. This means that 2 out of 5 Indonesians have osteopenia. This means that 2 out of 5 Indonesians have osteopenia, which puts them at risk for osteoporosis and fractures. ${ }^{(7)}$

In this study, the subjects who were willing to take part in the study were 38 out of 89 people who were included in the list of subjects who had been selected according to the inclusion criteria.

At the time of data collection, the mean age of the subjects was $66.33 \pm 8.542$ years. All subjects were over 45 years old and had entered menopause with an age range of 51 years to 85 years. Study conducted by Ceylan found that the age of onset of menopause in women was between the ages of 40 and 54 years with the mean age of menopause onset in Asia, namely 51.1 years. ${ }^{(8)}$ 


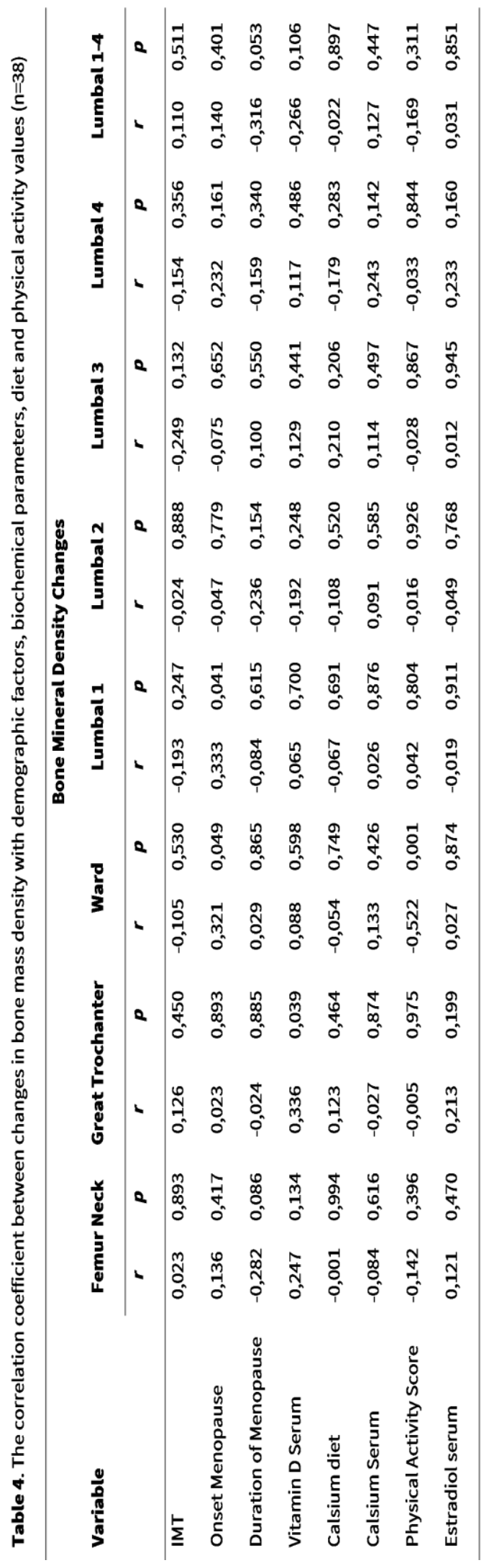

Bone density will decrease in time from per menopause to postmenopause. There was only a slight change in bone mass density at the time of early perimenopause, but a marked decrease in velocity at the end of perimenopause was seen with mean losses of $0.018 \mathrm{~g} / \mathrm{cm}^{2}$ in the vertebrae and $0.010 \mathrm{~g} / \mathrm{cm}^{2}$ in the pelvis each year. In postmenopausal conditions, there was greater bone loss, in amount $0.022 \mathrm{~g} / \mathrm{cm}^{2}$ in the vertebrae and $0.013 \mathrm{~g} / \mathrm{cm}^{2}$ in the pelvis each year. ${ }^{(9)}$

In contrast to the results of this study, 38 subjects had an increase in bone mass density in most regions of interest measured by BMD except lumbar 1-4.From the interviews that have been conducted, it is known that 15 subjects still consume bisphosphonates routinely and 24 other subjects have taken bisphosphonates when diagnosed with osteoporosis even though they are not currently taking them because they are already in a condition of osteopenia.

It is known that bisphosphonates are able to suppress bone turnover, prevent bone loss and maintain bone architecture by binding firmly to the bone surface and by inhibiting the enzyme farnesyl pyrophosphate synthase, which is required for osteoclast cytoskeleton formation, thereby inhibiting bone resorption. ${ }^{(10)}$

A study conducted by Diab, et al also found that the effect of bisphosphonate therapy can last for 3-6 months with a steady state level that can last for 10 years on continuous therapy. ${ }^{(11)}$

The onset of menopause is one of the factors that determine bone mass density in women. There are 2 phases of bone mass loss in women, namely the initial phase when the process occurs predominantly in the trabecular bone and begins at menopause which occurs due to estrogen deficiency which results in increased bone resorption and reduced bone formation activity. This phase is defined as menopause-related bone loss. After 4-8 years, there is a subsequent phase showing persistent activity, slower bone loss in cortical and 


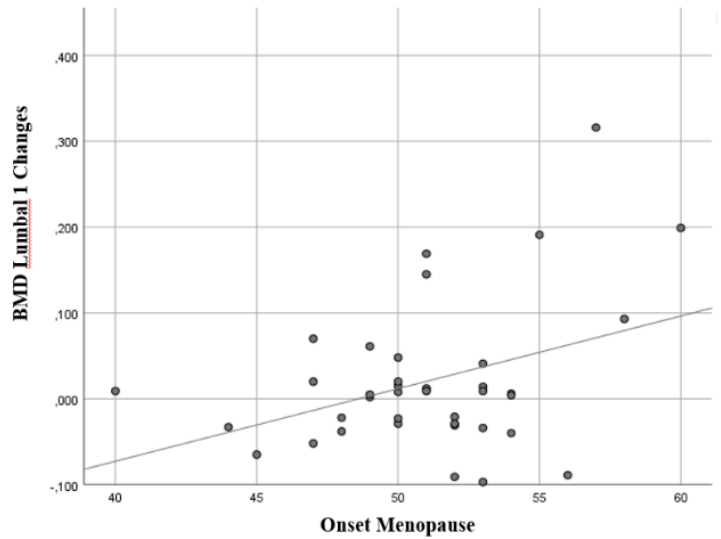

Figure 1. Scatter plot and correlation between menopause onset and BMD Lumbal 1 changes $(r=0,321, p=0,04)$

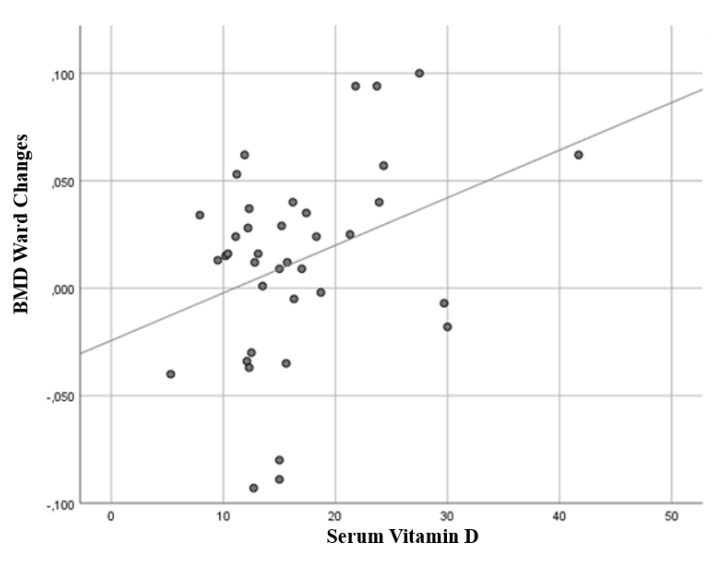

Figure 3. Scatter plot and correlation between serum vitamin $\mathrm{D}$ and BMD Ward's changes $(\mathrm{r}=0,336, \mathrm{p}=0,036)$

trabecular bone and mainly due to decreased bone formation processes. This phase is defined as age-related bone loss, which can also occur in men. During the menopausal transition period, the mean reduction in bone mass density is about $10 \%$. Nearly half of these women lose bone mass density which occurs more rapidly, about $10-20 \%$ during the 5-6 years of perimenopause. About 25\% of postmenopausal women can be classified as patients who lose bone mass rapidly. ${ }^{(12)}$

Greater changes in bone mass density were observed in women with late onset. However, bone mass density in women with late onset was better than in women with early onset of menopause. $^{(13)}$

Vitamin D insufficiency is known to be a common risk factor for osteoporosis associated with increase bone remodeling and lower bone mass density. Bone turnover is a balance of

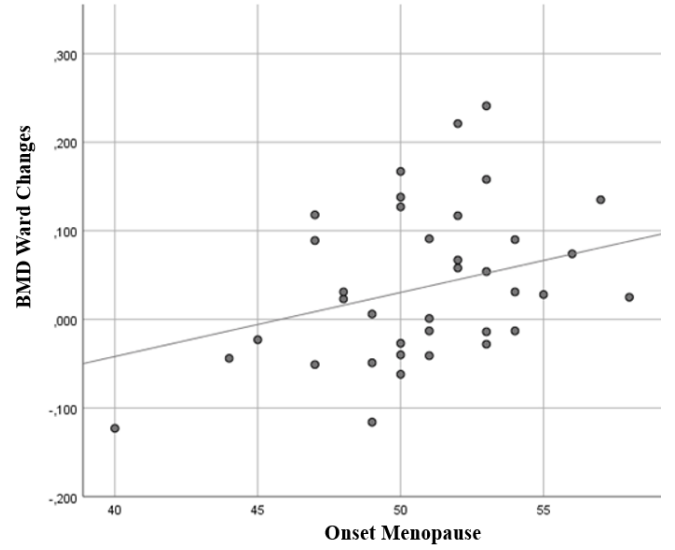

Figure 2. Scatter plot and correlation between menopause onset : BMD Ward's changes $(r=0,333, p=0,04)$

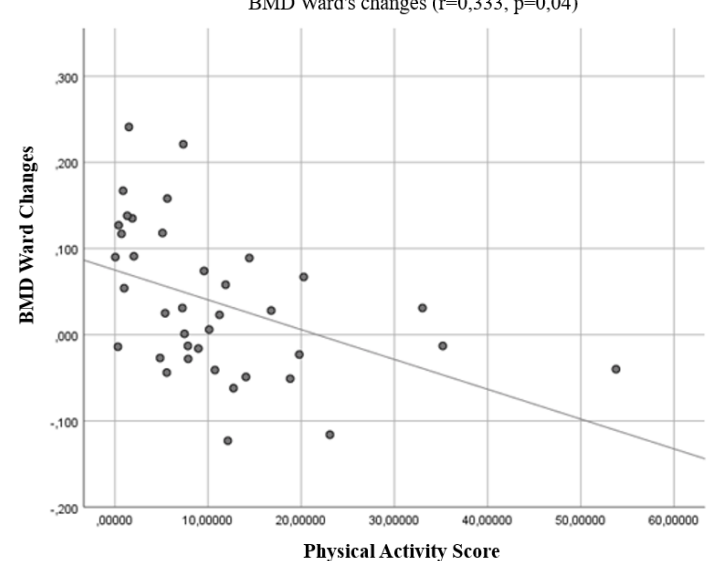

Figure 4. Scatter plot and correlation between Physical Activity Score and BMD Ward's changes $(r=-0,532, p<0,01)$

osteoblast function, which differentiates from mesenchymal stem cells, and osteoclasts, which originate from hematogenous cells and are the result of fusion of monocytes. In conditions of normal vitamin D levels, vitamin $D$ binds to vitamin $D$ receptors on mature osteoblasts which inhibits RANKL / OPG synthesis in osteoclasts so that the number of osteoclasts will decrease and result in decreased bone resorption and increase the speed of bone formation. The final result is increased cortical and trabecular bone mass density. However, in the presence of excess vitamin D levels, after vitamin D binds to vitamin $D$ receptors on osteoprogenitor cells and pre-osteoblasts, there will be an increase in RANKL/OPG synthesis which results in an increase in the number of osteoclasts. This will increase bone resorption, especially the trabecular bone. In addition, the increased 
levels of vitamin $D$ also increase the inhibition of bone mineralization that occurs both locally and systemically results osteomalacia. ${ }^{(14)}$

In conditions of vitamin D deficiency, active vitamin $\mathrm{D}$ metabolites will also decrease, followed by a decrease in calcium levels so that it affects bone mineralization. Then, parathyroid hormone levels will increase, stimulating the renal hydroxylation of vitamin D into active vitamin D metabolites until normal levels can be met. Increased parathyroid hormone levels also stimulate bone turnover resulting in loss of bone mass density. In this condition, active vitamin D metabolites will be at normal levels and the process of calcium absorption in the intestine can run optimally, but at that time bone resorption has occurred. If this condition occurs for a long time, osteoporosis will occur. ${ }^{(15)}$

Vitamin D levels are associated with bone mass density, not only in subjects with vitamin $D$ deficiency but also in subjects with vitamin $D$ deficiency. In cross-sectional studies, the association between serum vitamin $D$ levels and pelvic bone mass density has been observed. The density of the femoral neck bone mass will increase until the serum vitamin $D$ level is $90 \mathrm{nmol} / \mathrm{L}$. In another study, it was found that the total bone mass density in the pelvis and trochanter increased to a serum vitamin D level of $50 \mathrm{nmol} / \mathrm{L} .{ }^{(16)}$

The condition of low serum vitamin $D$ levels is often associated with low endogenous vitamin $D$ synthesis and low intake of vitamin $D$ from daily food and vitamin D supplements. Therefore, there is often a deficiency of vitamin $D$ levels in populations who do not consume vitamin D. ${ }^{(16)}$

Physical activity has a positive effect on bone mass density. Exercise prevents bone loss and, in some cases, increases bone mass density. However, the right type of physical activity, intensity, duration and frequency of physical activity is not clearly understood..$^{(17)}$
Physical activity can create a strain in the bone that causes micro damage in the bone structure. This condition will activate osteoblasts to perform remodeling so that there is repair. After remodeling occurs, the bones will be able to withstand the load previously applied so that it is called positive skeletal adaptation. This process can occur without symptoms. However, when physical activity is obtained continuously in excessive intensity it may result in more micro damage than the ability of osteoblasts repair. This results in the accumulation of micro damage which in turn fractures the bone. ${ }^{(18)}$

Increased vertebral bone density can be achieved by engaging in physical activity that combines resistance exercise, aerobic exercise and impact exercise. Various physical activities that are suitable for postmenopausal women to prevent and also useful as osteoporosis therapy include: weight lifting, walking, running, jumping, climbing, and also water sports such as moderate intensity swimming. However, postmenopausal women should exercise caution in physical activity to prevent the risk of injury or fracture. ${ }^{(19)}$

The findings in this study found a significant but negative correlation between changes in Ward's bone mass density and the value of physical activity using BPAQ as a measuring tool. BPAQ is a relatively straightforward method for finding the relationship between physical activity and bone mass density. ${ }^{(20)}$ From the study conducted by $\mathrm{Ng}$, et al it was found that BPAQ values were very consistent with tibial bone parameters in older women. ${ }^{(21)}$ However, the small change in bone mass density in subjects who perform more physical activity can also be understood that the bone mass density is in good condition so that when the subject enters menopause, the bone mass density does not decrease rapidly.

There are several limitations to this study. First, the reinforcement therapy is a process that occurs over a long period of time. Many 
other factors can affect the process of treatment, one of which is anti-osteoporosis drugs that were consumed by previous patients. Second, some of the respondents' ages were over 60 years old, which made it difficult for respondents to record their diet patterns, thereby reducing the validity of the data recorded. However, various ways have been made to reduce errors. Third, the age of the respondents who are at the age of menopause makes it difficult to remember the types of physical activity they have done, the frequency and intensity of physical activity in the past.

\section{O N C L U S I O N}

Onset of menopause, physical activity, and vitamin $D$ had a significant association with changes in bone mass density. Furthermore, regarding vitamin $\mathrm{D}$, postmenopausal women can be provided with information regarding the importance of vitamin $D$ in the process of reinforcement so that they can consume foods and supplements that contain vitamin $D$ and also sunbathe in the morning so that endogenous vitamin $D$ synthesis can run.

This study is expected to contribute knowledge about the risk factors that cause changes in bone mass density in postmenopausal women with osteopenia. In addition, it can be used as a reference in interventions that will be used in Indonesia, especially in Malang, to prevent osteoporosis in postmenopausal women who have experienced osteopenia.

\section{REFERE NCES}

1. Mithal A, Bansal B, Kyer CS, Ebeling P. The AsiaPacific Regional Audit-Epidemiology, Costs, and Burden of Osteoporosis in India 2013: A report of International Osteoporosis Foundation. Indian J Endocrinol Metab. 2014 Jul;18(4):449-54. doi: 10.4103/2230-8210.137485. PMID: 25143898; PMCID: PMC4138897].

2. Kementerian Kesehatan R. Infodatin pusat data dan informasi kementerian kesehatan RI. Situasi Gangguan Penglihatan dan Kebutaan Jakarta Selatan. 2015.
3. Karaguzel G, Holick MF. Diagnosis and treatment of osteopenia. Rev Endocr Metab Disord. 2010 Dec;11(4):237-51.

doi: 10.1007/s11154-010-9154-0. PMID: 21234807]

4. Iqbal SM, Qamar I, Zhi C, Nida A, Aslam HM. Role of Bisphosphonate Therapy in Patients with Osteopenia: A Systemic Review. Cureus. 2019 Feb 27;11(2):e4146.

doi: 10.7759/cureus.4146. PMID: 31058029; PMCID: PMC6488345].

5. Weeks BK, Beck BR. The BPAQ: a bone-specific physical activity assessment instrument. Osteoporos Int. 2008 Nov;19(11):1567-77.

doi: 10.1007/s00198-008-0606-2. Epub 2008 Apr 15. PMID: 18414964]

6. Lian IA, Åsberg A. Should total calcium be adjusted for albumin? A retrospective observational study of laboratory data from central Norway. BMJ open. 2018;8(4):e017703.

doi: $\quad$ http://dx.doi.org/10.1136/bmjopen-2017017703]

7. The Composition of Bone. Primer on the Metabolic Bone Diseases and Disorders of Mineral Metabolism. 2018:84-92. doi: $10.1002 / 9781119266594]$

8. Ceylan B, Özerdoğan N. Factors affecting age of onset of menopause and determination of quality of life in menopause. Turk J Obstet Gynecol. 2015 Mar;12(1):43-49.

doi: 10.4274/tjod.79836. Epub 2015 Mar 15. PMID: 28913040; PMCID: PMC5558404]

9. Finkelstein JS, Brockwell SE, Mehta V, Greendale GA, Sowers MR, Ettinger B, Lo JC, Johnston JM, Cauley JA, Danielson ME, Neer RM. Bone mineral density changes during the menopause transition in a multiethnic cohort of women. J Clin Endocrinol Metab. 2008 Mar;93(3):861-8.

doi: 10.1210/jc.2007-1876. Epub 2007 Dec 26. PMID: 18160467; PMCID: PMC2266953]

10. Tella SH, Gallagher JC. Prevention and treatment of postmenopausal osteoporosis. J Steroid Biochem Mol Biol. 2014 Jul;142:155-70.

doi: 10.1016/j.jsbmb.2013.09.008. Epub 2013 Oct 29. PMID: 24176761; PMCID: PMC4187361]

11. Diab DL, Watts NB. Bisphosphonate drug holiday: who, when and how long. Ther Adv Musculoskelet Dis. 2013 Jun;5(3):107-11.

doi: 10.1177/1759720X13477714. PMID: 23858334; PMCID: PMC3707342]

12. Ji MX, Yu Q. Primary osteoporosis in postmenopausal women. Chronic Dis Transl Med. 2015 Mar 21;1(1):9-13.

doi: 10.1016/j.cdtm.2015.02.006. PMID: 29062981; PMCID: PMC5643776]

13. Fugiel J, Ignasiak Z, Skrzek A, Stawińska T. Evaluation of Relationships between Menopause Onset Age and Bone Mineral Density and Muscle 
Strength in Women from South-Western Poland. Biomed Res Int. 2020 Jun 10;2020:5410253. doi: $10.1155 / 2020 / 5410253]$

14. Goltzman D. Functions of vitamin D in bone. Histochem Cell Biol. 2018 Apr;149(4):305-312. doi: 10.1007/s00418-018-1648-y]

15. Lips $P$, van Schoor NM. The effect of vitamin D on bone and osteoporosis. Best Pract Res Clin Endocrinol Metab. 2011 Aug;25(4):585-91. doi: 10.1016/j.beem.2011.05.002. PMID: 21872800]

16. Alissa EM, Qadi SG, Alhujaili NA, Alshehri AM, Ferns GA. Effect of diet and lifestyle factors on bone health in postmenopausal women. J Bone Miner Metab. 2011;29(6):725-35.

17. Segev D, Hellerstein D, Dunsky A. Physical Activitydoes it Really Increase Bone Density in Postmenopausal Women? A Review of Articles Published Between 2001-2016. Curr Aging Sci. 2018;11(1):4-9. doi: $10.2174 / 1874609810666170918170744]$

18. Hart NH, Nimphius S, Rantalainen $\mathrm{T}$, Ireland A, Siafarikas A, Newton RU. Mechanical basis of bone strength: influence of bone material, bone structure and muscle action. J Musculoskelet Neuronal Interact. 2017 Sep 1;17(3):114-139. [PMID: 28860414; PMCID: PMC5601257]

19. Moreira LD, Oliveira ML, Lirani-Galvão AP, et al. Physical exercise and osteoporosis: effects of different types of exercises on bone and physical function of postmenopausal women. Arq Bras Endocrinol Metabol. 2014 Jul;58(5):514-22. doi: $10.1590 / 0004-2730000003374$.

20. Kim S, So WY, Kim J, Sung DJ. Relationship between Bone-Specific Physical Activity Scores and Measures for Body Composition and Bone Mineral Density in Healthy Young College Women. PLoS One. 2016 Sep 2;11(9):e0162127.

doi: 10.1371/journal.pone.0162127. PMID: $27589270 ;$ PMCID: PMC5010201.

21. Ng CA, McMillan LB, Beck B, Humbert L, Ebeling PR, Scott $D$. Associations between physical activity and bone structure in older adults: does the use of selfreported versus objective assessments of physical activity influence the relationship? Osteoporos Int. 2020 Mar;31(3):493-503.

doi: 10.1007/s00198-019-05208-y] 